\title{
PENGARUH LAJU ALIRAN UDARA TERHADAP HAMBATAN TERMAL HEAT SINK UNTUK PENDINGIN ELEKTRONIK
}

\author{
Tri Ayodha Ajiwiguna', Abdillah Barkah², Abrar ${ }^{3}$ \\ 1,2,3, Teknik Fisika, Fakultas Teknik Elektro, Universitas Telkom \\ tri.ayodha@telkomuniversity.ac.id1, abdillahbarkah14@telkomuniversity.ac.id², \\ abrarselah@telkomuniversity.ac.id ${ }^{3}$
}

\begin{abstract}
Abstrak
Pengukuran hambatan termal dari lima jenis geometri heat sink berbeda untuk keperluan pendingin elektronik dilakukan pada penelitian ini. Sistem alat uji hambatan termal yang dibuat terdiri dari modul termoelektrik sebagai sumber panas, stainless steel sebagai material rujukan, dan kipas untuk memvariasikan laju aliran udara. Temperatur udara, bagian bawah dan atas material rujukan diukur dengan menggunakan termokopel tipe T. Laju aliran udara diatur sehingga memiliki nilai dari 0.06 sampai dengan $0.16 \mathrm{~m}^{3} / \mathrm{s}$. Disipasi kalor diukur dengan menghitung laju aliran kalor konduksi yang terjadi pada material rujukan. Dari pengukuran tersebut, hambatan termal dari masing-masing heat sink kemudian dihitung dan dibandingkan dengan berbagai nilai laju aliran udara. Dari hasil yang didapatkan secara umum bahwa semakin besar laju aliran udara mengakibatkan menurunnya hambatan termal dari heat sink
\end{abstract}

Kata Kunci: Hambatan termal, Laju aliran volume udara, Perpindahan panas, heat sink

\begin{abstract}
Thermal resistance of five different geometry of heat sinks for electronics cooling are measured in this study. The measurement system is made of thermoelectric module as a heater, stainless steel as material reference, and fan to vary the air flow rate. The surface area of material reference is conditioned so that as large as the thermoelectric module. The temperature of air, top and bottom of material reference are measured by T-type thermocouple. The flow rate varies from 0.06 to $0.16 \mathrm{~m}^{3} / \mathrm{s}$. Heat dissipations are then measured by calculating the heat conduction at material reference. Thermal resistances of the heat sinks are then calculated and compared. The result shows that the thermal resistances are decreased with the increasing of air flow rate.
\end{abstract}

Keywords: Thermal Resistance Measurement, Air Flow, Heat Sink, Heat Transfer

\section{Pendahuluan}

Perkembangan teknologi elektronik pada saat ini semakin pesat, terutama pada performa. Hal ini menyebabkan daya disipasi komponen elektronik semakin besar. Di lain sisi, performa dan umur dari sebuah komponen elektronik juga sangat tergantung dari temperaturnya. Tanpa adanya manajemen termal yang baik, keadaan overheating akan terjadi sehingga merusak komponen tersebut. Salah satu solusi hal tersebut adalah menggunakan komponen heat sink untuk membantu melepaskan kalor dari komponen elektronik ke lingkungan [12].

Heat sink adalah komponen yang terbuat dari bahan berkonduktifitas termal tinggi yang terdiri dari pelat dasar dan sirip-sirip untuk memperluas kontak permukaan. Pada saat dipasang pada komponen elektronik, konduksi kalor terjadi dari pelat dasar ke sirip dan kemudian konveksi kalor dari sirip ke lingkungan [3]. Untuk meningktkan konveksi kalor, seringkali heat sink dilengkapi dengan kipas. Penelitian dalam pemanfaatan heat sink telah banyak dilakukan termasuk memanfaatkan disipasi komponen elektronik untuk sumber energi [4-6]. Hambatan termal yang didefinisikan sebagai rasio antara perbedaan temperatur dengan disipasi kalor menjadi parameter penting yang menunjukan kemampuan sebuah heat sink. Pengukuran hambatan termal untuk komponen electronic dapat dilakukan dengan mengukur perbedaan temperatur antara dua titik dan mengukur daya disipasinya [7]. Dalam studi ini, pengaruh laju aliran udara terhadap besarnya hambatan termal diinvestigasi pada lima jenis geometri heat sink berbeda.

\section{Landasan Teori}

\subsection{Perpindahan Kalor}

Perpindahan kalor yaitu ilmu untuk mempresentasikan perpindahan energi yang terjadi karena adanya perbedaan temperatur diantara benda atau bahan. Energi yang berpindah ini dinamakan kalor. Perpindahan kalor ini 
menjelaskan bagaimana energi kalor itu berpindah dari satu benda ke benda lain, begitu juga dapat meramalkan laju perpindahan yang terjadi pada kondisi-kondisi tertentu[3].

\subsubsection{Konduksi}

Perpindahan kalor secara konduksi terjadi akibat adanya perpindahan energi dari partikel yang memiliki energi lebih tinggi ke partikel yang energinya lebih rendah. Perpindahan kalor secara konduksi dapat dirumuskan sebagai berikut:

$$
q=k A \frac{\left(T_{1}-T_{2}\right)}{l}
$$

Keterangan:

$$
\begin{aligned}
& q \quad=\text { laju perpindahan kalor (Watt) } \\
& \left(T_{1}-T_{2}\right) / l=\text { gradien perpindahan kalor } \quad(\mathrm{K} / \mathrm{m}) \\
& \mathrm{k} \quad=\text { konduktifitas termal } \quad(\mathrm{W} / \mathrm{m} . \mathrm{K}) \\
& A \quad=\text { luas permukaan benda } \quad\left(\mathrm{m}^{2}\right)
\end{aligned}
$$

Perpindahan kalor secara konduksi dapat dapat dianalogikan bahwa laju kalor mengalir dari suhu tinggi $\left(T_{1}\right)$ ke suhu yang lebih rendah $\left(T_{2}\right)$ yang menembus luas bidang $(A)$ dengan ketebalan ( $l$ ) yang memiliki nilai konduktifitas termal bahan $(K)$
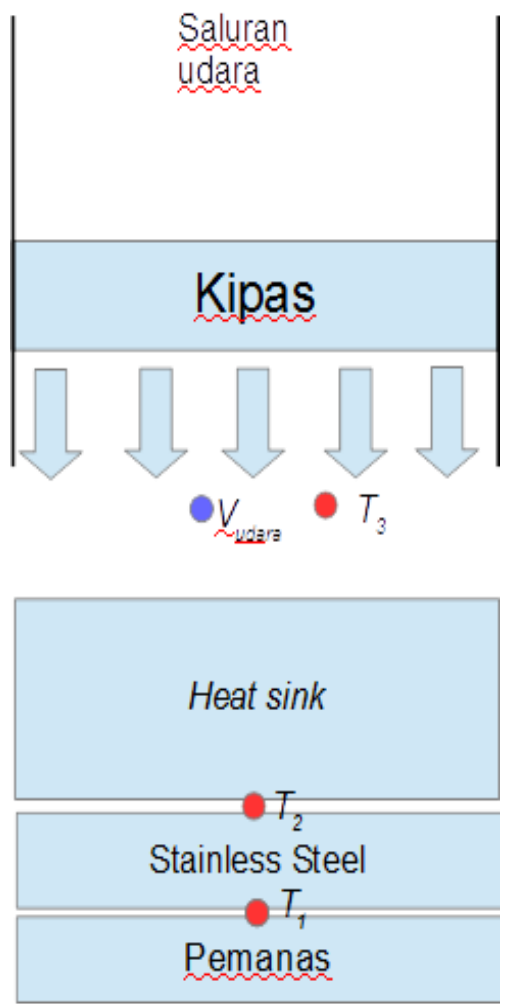

Gambar 1. Skema percobaan alat ukur hambatan termal

\subsubsection{Konveksi Paksa}

Perpindahan kalor secara konveksi yaitu perpindahan panas yang terjadi antara permukaan padat dengan fluida (cairan/gas) yang mengalir disekitarnya. Persamaan dasar untuk perpindahan kalor secara konveksi dapat dirumuskan sebagai

\begin{tabular}{|c|c|c|}
\hline$q$ & $=$ laju perpindahan kalor & (Watt) \\
\hline$T_{w}$ & $=$ suhu permukaan & $(\mathrm{K})$ \\
\hline$T_{\infty}$ & $=$ suhu fluida & $(\mathrm{K})$ \\
\hline$A$ & $=$ luas permukaan & $\left(\mathrm{m}^{2}\right)$ \\
\hline $\mathrm{h}$ & = koefisien konveksi & $\left(\mathrm{W} / \mathrm{m}^{2} \cdot \mathrm{K}\right)$ \\
\hline
\end{tabular}
berikut:

$$
q=h . A .\left(T_{w}-T_{\infty}\right)
$$

Keterangan :

Untuk menentukan nilai koefisien konveksi, maka perlu diketahui bilangan Nusselt, yaitu perbandingan antara perpindahan kalor konveksi dan konduksi pada fluida [3]. secara matematis dapat ditulis:

$$
h=\frac{k N u}{L_{c}}
$$

Keterangan:

$$
\begin{array}{ll}
k & =\text { konduktiftas termal fluida } \\
N u & =\text { Bilangan Nusselt } \\
L_{c} & =\text { Panjang karakteristik }
\end{array}
$$

Bilangan Nusselt sendiri merupakan fungsi dari bilangan Reynold dan Prandtl, secara empiris dapat ditulis dalam bentuk:

$$
N u=f\left(R_{e}, L_{c}, \mathrm{P}_{r}\right)
$$

\subsubsection{Hambatan Termal}

Hambatan termal merupakan sifat kemampuan suatu bahan menghambatan laju aliran kalor yang mengalir dengan perbedaan temperatur antar sisinya. Dapat dituliskan persamaanya seperti berikut.

$$
R=\frac{\square T}{q}
$$

Keterangan :

$$
\begin{array}{lll}
R & =\text { Hambatan Termal pada material } & \left({ }^{\circ} \mathrm{C} / \mathrm{W}\right) \\
\Delta \mathrm{T} & =\text { Perbedaan temperatur } & \left({ }^{\circ} \mathrm{C}\right) \\
q & =\text { Laju perpindahan kalor } & \text { (Watt) }
\end{array}
$$

\section{Pengukuran}

Gambar 1 menunjukkan skema alat yang dibuat untuk mengukur besarnya hambatan termal sebuah heat sink. Modul termoelektrik digunakan sebagi pemanas sedangkan stainless steel digunakan sebagai material rujukan karena nilai konduktiftas termalnya sudah diketahui. 


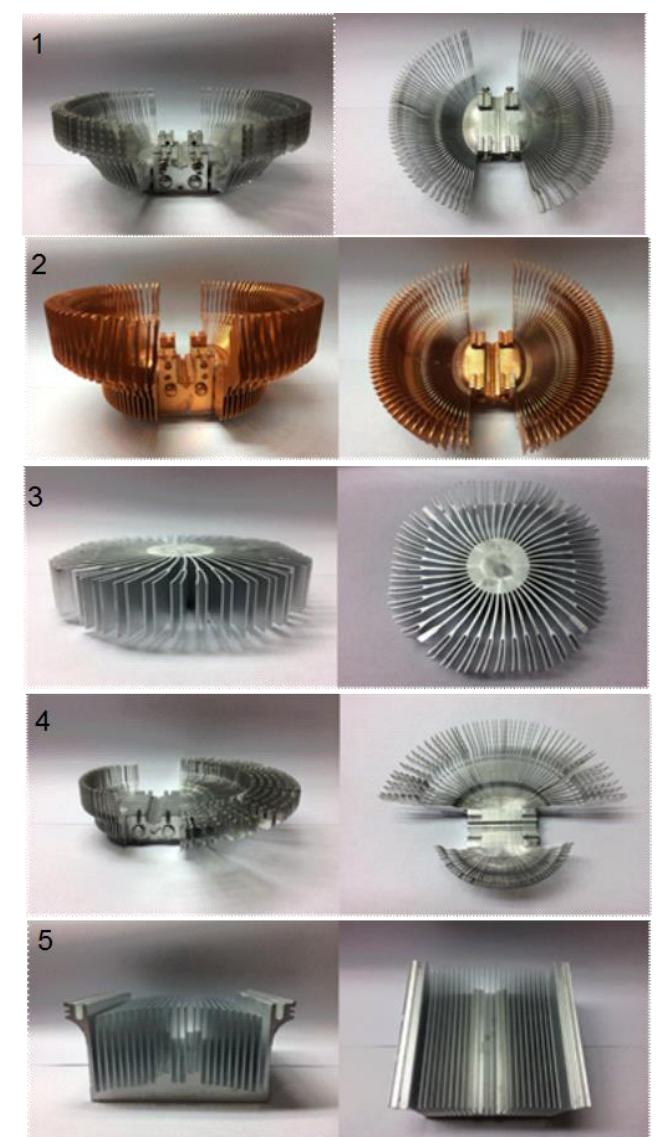

Gambar 2. Lima jenis geometri heatsink yang diuji

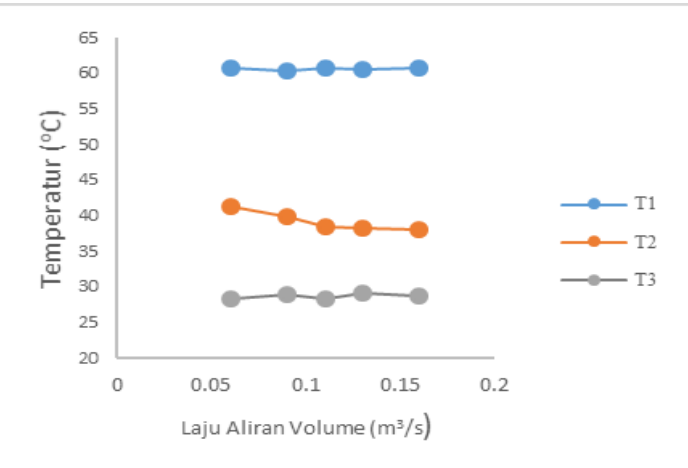

Gambar 3. Profil temperatur pada setiap titik pengukuran untuk heatsink 1

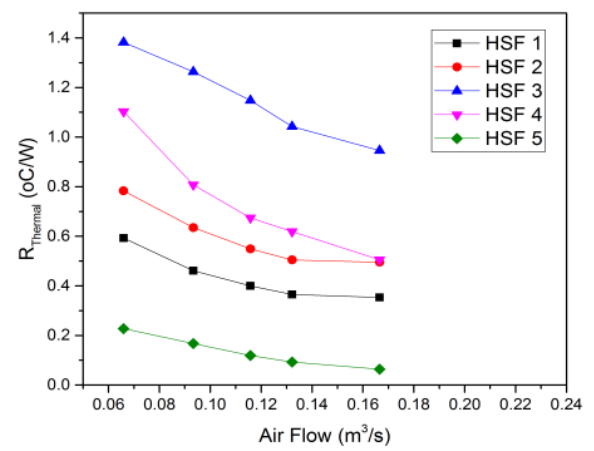

Gambar 4. Pengaruh laju aliran volume
terhadap hambatan termal
Lima jenis heat sink yang diuji terlihat pada Gambar 2. Gambar sebelah kiri memperlihatkan tampak samping sedangkan sebelah kan memperlihatkan tampak atas. Saluran udara yang dilengkapi kipas digunakan untuk mengalirkan udara ke sirip-sirip heat sink.

$T_{1}$ sampai $T_{3}$ merupakan titik pengukuran temperatur dengan menggunakan termokopel tipe T. Untuk pengukuran kecepatan udara digunakan anemometer yang dilakukan beberapa titik sehingga didapatkan rata-ratanya. Semua pengukuran dilakukan secara bersama-sama dan data diambil setelah kondisi tunak tercapai [8]. Disipasi kalor dapat dihitung dengan menghitung laju aliran kalor secara konduksi yang terjadi di material rujukan, yaitu:

$$
q_{d i s}=\frac{k A\left(T_{1}-T_{2}\right)}{L}
$$

Dengan $k, A$, dan $L$ masing-masing adalah konduktifitas termal, luas permukaan, dan tebal dari materal rujukan.

\section{Hasil dan Analisis}

Dari hasil pengukuran, secara umum didapatkan data temperatur yang memiliki karakteristik seperti yang ditunjukkan pada gambar 3 yaitu $T_{1}>T_{2}>T_{3}$. Data yang didapatkan menujukkan kalor mengalir dari bagian bawah ke bagian atas material rujukan kemudian ke udara lingkungan.

Perbandingan besarnya hambatan termal pada masing-masing heat sink ditunjukkan oleh gambar 4. Terlihat bahwa besarnya hambatan termal akan turun jika laju aliran udara meningkat. Hal ini dikarenakan konveksi kalor dari sirip-sirip heat sink ke udara lingkungan meningkat.

Perpindahan kalor dari heat sink ke udara terjadi secara konveksi paksa. Berdasarkan persamaan 4, salah satu parameter yang mempengaruhi besarnya nilai koefisien konveksi adalah bilangan Reynold yaitu perbandingan antara momen inersia dengan viskositasnya.

Bilangan Reynold secara matematis dapat dihitung dengan:

$$
\mathrm{R}_{e}=\frac{\rho V L_{c}}{\mu}
$$

Dengan $\rho, V$, dan $\mu$ masing-masing adalah massa jenis, kecepatan fluida, dan viskositas dinamik.

Heat sink jenis 5 memiliki nilai hambatan yang paling rendah sedangkan heat sink ke tiga paling tinggi. Hal ini membuktikan bahwa dimensi dan geometri dari heat sink juga sangat berperngaruh terhadap hambatan termal. Heat sink yang ke empat memikiki nilai hambatan termal 
yang sangat sensitif. Hal ini terlihat dari perubahan niai hambaan termal yang paling besar jika laju aliran udaranya dinaikkan.

\section{Kesimpulan}

Dari hasil penelitian tentang pengaruh laju aliran udara terhadap hambatan termal heat sink fan, kesimpulan yang didapat antara:

1. Geometri dari sebuah heat sink sangat berpengaruh terhadap hambatan termal.

2. Semakin tinggi laju aliran volume udara dari 0.06-0.16 $\mathrm{m}^{3} / \mathrm{s}$, maka hambatan termalnya akan semakin rendah. Hal ini terjadi karena perubahan laju aliran udara dapat merubah koefisien konveksi, sehingga perpindahan konveksi mengalami peningkatan dan hambatan termal akan semakin rendah.

\section{Daftar Pustaka}

[1] Yunianto, B. "Pengujian Perpindahan Panas Konveksi Pada Heat Sink Jenis Extruded", ROTASI, 1-6. 2008

[2] Tinton Dwi Atmaja, G. P. Managemen Termal Heat Sink Pada Modul Kendali Motor Kendaraan Hibrid. ISBN 978-604-19028-0-6, 1-5. 2011

[3] Cengel, Y.A., "Heat Transfer : A Practical Approach" Second Edition. New york: McGraw-Hill., 2013

[4] Nuzul Hesty Pranita, Kiki Azura, Abrar Ismardi, Tri Ayodha Ajiwiguna, IP Handayani. "Implementing thermoelectric generator on CPU processor", ICCEREC. 2015

[5] Tresna Dwi Sugiarto, I. P, Analisis dan Simulasi Distribusi Panas pada Heat Sink Processor CPU dengan Comsol Multiphysics, eproceeding telkom unversity, 1-6. 2015

[6] Ko-Ta Chiang, F.-P. Chang. (2006). "Aplication of Response Surface Methodology in The Parametric Optimazion of a Pin-Fin Type Heat Sink" International Communications in Heat and Mass Transfer, Volume 3 Issue 77, pp 836-835. 2006

[7] T. A. Ajiwiguna, H. S. Han, S. Y. Kim, "Improved junction temperature measurement for high power LED", ARPN J. Eng. Appl. Sci., vol. 11, no. 2, pp. 1030-1034, Jan. 2016.

[8] Bentley, J. P. Principles of Measurement System. London: Longman Group UK. 1995 